\title{
Anti-leishmanial activity of betulin derivatives
}

\author{
Sami Alakurtti ${ }^{1,2}$, Pia Bergström ${ }^{2}$, Nina Sacerdoti-Sierra ${ }^{3}$, Charles L Jaffe ${ }^{3}$ and Jari Yli-Kauhaluoma ${ }^{1}$ \\ Leishmanicidal activity of $\mathbf{2 4}$ derivatives of naturally occurring and abundant triterpenes belonging to the lupane series, betulin, \\ betulinic acid and betulonic acid, is described in this study. The easily modified positions of the lupane skeleton, the hydroxy \\ groups of C-3 and C-28, as well as the carbon-carbon double bond C-20-C-29 were used as a starting point to prepare \\ a library of triterpenoid derivatives for bioactivity studies. The compounds were evaluated against Leishmania donovani axenic \\ amastigotes on a microplate assay at $50 \mu \mathrm{M}$. $\mathrm{Gl}_{50}$ values of the most effective compounds were evaluated, as well as their \\ cytotoxicity on the human macrophage cell line THP-1, and anti-leishmanial activity against $L$. donovani-infected THP-1 \\ macrophages was determined. Betulonic acid was the most potent derivative, yielding a $\mathrm{Gl}_{50}$ value of $14.6 \mu \mathrm{m}$. Promising \\ and distinct structure-activity relationships were observed, and these compounds can be regarded as significant lead molecules \\ for further improvement and optimization.
}

The Journal of Antibiotics (2010) 63, 123-126; doi:10.1038/ja.2010.2; published online 5 February 2010

Keywords: antiprotozoal agents; betulin; betulinic acid; Leishmania sp.; Terpenoids

\section{INTRODUCTION}

Leishmaniases are diseases caused by protozoan parasites that affect millions of people in more than 88 countries worldwide. These parasites are transmitted by female sand flies belonging to the genus Phlebotomus and Lutzomyia in the Old and New World, respectively. Leishmaniasis causes three main forms of clinical disease: (1) visceral leishmaniasis, the most severe form, is usually fatal if not treated and affects internal organs such as the liver, spleen and bone marrow; (2) mucocutaneous leishmaniasis, a chronic form, causes extensive destruction and disfiguration of the nasopharynx region; and (3) cutaneous leishmaniasis, the mildest form, is usually self-healing within a few months to years, causing scarring at the site of the lesion(s). First-line drugs include pentavalent antimony $\left(\mathrm{Sb}^{\mathrm{v}}\right) \mathrm{com}-$ pounds, pentamidine or amphotericin B. All these drugs are administrated by injection and require clinical supervision or hospitalization because of the possibility of severe side effects. However, parasite resistance to $\mathrm{Sb}^{\mathrm{v}}$ drugs has resulted in the discontinued use of these compounds in some endemic regions for visceral leishmaniasis. ${ }^{1}$ Liposomal amphotericin B shows reduced toxicity, but is prohibitively expensive for use in less-developed countries. Recently, miltefosine, an alkylphospholipid derivative and the first orally administered drug, has been approved for use in India. However, the teratogenic effects of this drug prevent its use in pregnant women, ${ }^{2,3}$ and parasite resistance is easily generated in the laboratory. ${ }^{4}$ As such, there is an urgent need for the development and testing of new compounds for the treatment of all clinical forms of leishmaniasis.

Betulin 1 (lup-20(29)-ene-33,28-diol) is an abundant naturally occurring triterpene found in the plant kingdom (Figure 1). It is the principal extractive (up to $30 \%$ of dry weight) of the bark of whitebarked birch trees (Betula sp.). ${ }^{5}$ This pentacyclic triterpene can be converted into betulinic acid $2{ }^{6}{ }^{6}$ which has shown anti-inflammatory, ${ }^{7}$ antimalarial $^{8}$ and especially cytotoxic activity against several tumor cell lines by inducing apoptosis in cells. ${ }^{9,10}$ Some betulin derivatives have also shown remarkable anti-human immunodeficiency virus activity with new mechanisms of action. ${ }^{11,12}$ Structure-activity relationship studies and pharmacological properties of betulin and its derivatives have been reviewed recently. ${ }^{13}$

Previously, dihydrobetulinic acid $\mathbf{3}$ was examined as a new lead compound for anti-leishmanial therapy. ${ }^{14}$ It was shown that it targeted DNA topoisomerases I and II by preventing DNA cleavage and formation of an enzyme-DNA complex, which ultimately induced apoptosis in Leishmania donovani promastigotes and amastigotes in infected macrophages with an $\mathrm{IC}_{50}$ value of 2.6 and $4.1 \mu \mathrm{M}$, respectively. Parasitic burden in golden hamsters was reduced by $92 \%$ after a 6-week treatment with dihydrobetulinic acid $3\left(10 \mathrm{mg} \mathrm{kg}^{-1}\right.$ body weight). In another study, in which leishmanicidal inhibition activity of a plethora of natural products was screened, betulinic acid 2 isolated in small quantities from Betula platyphylla var. japonica was found to be weakly active against Leishmania major promastigotes, the extracellular form of the parasite, with an $\mathrm{IC}_{50}$ value of $88 \mu \mathrm{m} .{ }^{15}$ It was also noted that in triterpenes with ursane, oleanane or lupane skeletons, a carboxyl substituent was required for anti-leishmanial activity. In a related study, it was shown that a rare natural product, betulin aldehyde 4, obtained from Doliocarpus dentatus (Aubl.) showed in vitro activity against Leishmania amazonensis amastigotes in infected macrophages, reducing infection by $88 \%$ at $136 \mu \mathrm{M}$ and by

\footnotetext{
${ }^{1}$ Faculty of Pharmacy, Division of Pharmaceutical Chemistry, University of Helsinki, Helsinki, Finland; ${ }^{2}$ VTT Technical Research Centre of Finland, Espoo, Finland and ${ }^{3}$ Department of Microbiology and Molecular Genetics, IMRIC, The Hebrew University, Jerusalem, Israel

Correspondence: Professor J Yli-Kauhaluoma, Faculty of Pharmacy, Division of Pharmaceutical Chemistry, University of Helsinki, PO Box 56 (Viikinkaari 5 E), FI-00014 Helsinki, Finland.

E-mail: jari.yli-kauhaluoma@helsinki.fi

Received 6 November 2009; revised 29 December 2009; accepted 4 January 2010; published online 5 February 2010
} 


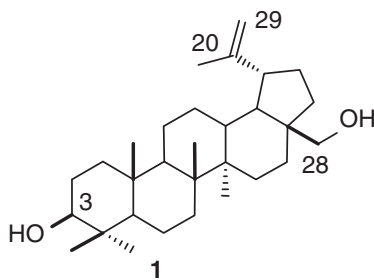

1<smiles></smiles>

2<smiles>CC(C)[C@H]1CCC2(C(=O)O)CC[C@]3(C)C(CCC4C5(C)CCC(O)C(C)(C)[C@H]5CCC43C)C12</smiles>

3<smiles>C=C(C)[C@H]1CCC2(C=O)CC[C@]3(C)C(CCC4[C@@]5(C)CCC(O)C(C)(C)[C@H]5CC[C@]43C)C12</smiles>

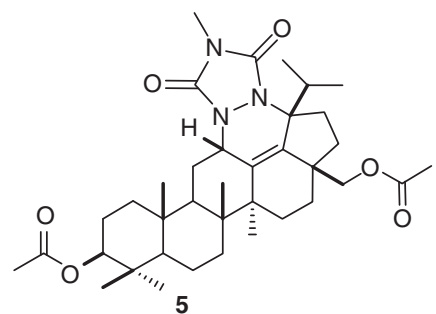

Figure 1 Chemical structures of betulin 1, betulinic acid 2, dihydrobetulinic acid 3, betulin aldehyde $\mathbf{4}$ and betulin heterocycloadduct between 3,28-di- 0 acetyllupa-12,18-diene and 4-methylurazine $\mathbf{5}$.

$58 \%$ at $68 \mu \mathrm{m} .{ }^{16}$ At these doses, 4 also showed some toxicity against peritoneal macrophages, with survival indices of 70 and $80 \%$, respectively. Previously, we studied anti-leishmanial activity of heterocyclic betulin derivatives, in which the heterocycloadduct between 3,28-di$\mathrm{O}$-acetyllupa-12,18-diene and 4-methylurazine 5 was the most effective derivative with a $\mathrm{GI}_{50}$ value of $8.9 \mu \mathrm{M}$ against $L$. donovani amastigotes. ${ }^{17}$ These results prompted us to investigate more closely the anti-leishmanial activity of 24 betulin derivatives that have been chemically modified in positions C-3, C-28 and C-20-C-29 of the lupane skeleton.

\section{RESULTS AND DISCUSSION}

We found that betulin $\mathbf{1}$ (isolated from Betula sp.) has moderate antileishmanial activity against $L$. donovani axenic amastigotes, showing $35 \%$ inhibition at $50 \mu \mathrm{m}$ in a microplate assay (Table 1). Acetylation, esterification or etherification of the hydroxy groups at C-3 or C-28 in most cases retained anti-leishmanial activity. We observed that $28-\mathrm{O}$ Cinnamoylbetulin 6 was totally inactive and 28-O-nicotinoylbetulin 7, 28-O-tetrahydropyranylbetulin 8, 28-O-chrysanthemoylbetulin 9 and betulinyl-28-O-carboxymethoxycarvacrolate $\mathbf{1 0}$ were only slightly active. Only 28-O-( $\mathrm{N}$-acetylanthraniloyl)betulin 11 and 28-O-bromoacetylbetulin 12 showed improved anti-leishmanicidal activity (59 and $86 \%$ inhibition at $50 \mu \mathrm{M}$, respectively), compared with 1 . In addition, 3-O-acetylbetulin $\mathbf{1 3}$ had similar anti-leishmanial inhibition activity compared with the starting material betulin 1 , whereas 3,28 di-O-acetylbetulin 14 and 3,28-di-O-levulinoylbetulin 15 were totally inactive.

Oxidation of 1 seems to have a beneficial effect on anti-leishmanial activity. Betulin aldehyde 4 displayed improved anti-leishmanial activity with a $64 \%$ inhibition at $50 \mu \mathrm{M}$. Betulinic acid 2 possessed moderate anti-leishmanial activity with a $40 \%$ inhibition at $50 \mu \mathrm{M}$. 28 O-Acetyl-3-oxobetulin 16 and betulonic aldehyde 17 showed moderate anti-leishmanial activity similar to the starting material $\mathbf{1}$, but betulonic acid $\mathbf{1 8}$ had remarkable anti-leishmanial activity with a $98 \%$ inhibition at $50 \mu \mathrm{M}$. Reduction of the carbon-carbon double bond of betulonic acid 18 to the corresponding dihydrobetulonic acid 19 decreased anti-leishmanial activity to $72 \%$ at $50 \mu \mathrm{m}$. Furthermore, methylation of betulonic acid $\mathbf{1 8}$ to methyl betulonate $\mathbf{2 0}$ decreased the inhibition activity at $50 \mu \mathrm{m}$ to $40 \%$. L-aspartyl amide of betulonic acid 21 showed reduced leishmanicidal activity compared with betu- lonic acid 18, with a $69 \%$ inhibition at $50 \mu \mathrm{M}$. Vanillyl betulonate 22 was totally inactive.

Removal of the C-3 hydroxy group of 1 resulted in 3-deoxy-2,3didehydrobetulin 23 , the anti-leishmanial activity of which diminished to $13 \%$ at $50 \mu \mathrm{m}$. Oxime derivatives $\mathbf{2 4}$ and $\mathbf{2 5}$ showed good leishmanicidal activities at $50 \mu \mathrm{M}$, with 69 and $73 \%$ inhibition, respectively. Moreover, betulin derivative $\mathbf{2 6}$ with a nitrile group at C-28 showed good anti-leishmanial activity with a $63 \%$ inhibition at $50 \mu \mathrm{m}$.

Derivatives $(12,18,19,21$ and 25) that showed the best antileishmanial activity on microplate assay at $50 \mu \mathrm{m}$ against $L$. donovani axenic amastigotes were selected for further investigations: $\mathrm{GI}_{50}$ values, cytotoxicity to the macrophage cell line THP-1 and anti-leishmanial activity against the L. donovani-infected macrophage cell line THP-1 were evaluated. Betulonic acid $\mathbf{1 8}$ showed the best $\mathrm{GI}_{50}$ value of $14.6 \mu \mathrm{M}$ on microplate assay against $L$. donovani axenic amastigotes, followed by L-aspartyl amide derivative 21 and oxime derivative 25, with $\mathrm{GI}_{50}$ values of 21.2 and $22.8 \mu \mathrm{M}$, respectively (Table 1 ). 28-OBromoacetylbetulin 12 and dihydrobetulonic acid 19 had moderate $\mathrm{GI}_{50}$ values of 34.9 and $56.0 \mu \mathrm{M}$, respectively. Cytotoxicity of derivatives 12, 18, 19, 21 and 25 was tested against the macrophage cell line THP-1 at concentrations of 50, 25 and $12.5 \mu \mathrm{M}$ (Table 2). Betulonic acid 18 showed cytotoxicity against the THP-1 cell line at all test concentrations. Dihydrobetulonic acid 19 and oxime derivative 25 showed cytotoxicity against the THP- 1 cell line at 50 and $25 \mu \mathrm{M}$, but at $12.5 \mu \mathrm{M}$ concentration, cytotoxicity of $\mathbf{1 9}$ and $\mathbf{2 5}$ was reduced to 22.0 and $13.6 \%$, respectively. L-aspartyl amide derivative 21 and $28-O-$ bromoacetylbetulin 12 were nontoxic to macrophage cell line THP-1 at all test concentrations.

Finally, anti-leishmanial activity of compounds 12, 19, 21 and 25 was tested against $L$. donovani-infected macrophage cell line THP-1, with concentrations that showed $<30 \%$ cytotoxicity to the THP- 1 cell line (Table 3). In all cases, anti-leishmanial activity was reduced when compared with that in the corresponding microplate assay with L. donovani axenic amastigotes. L-aspartyl amide derivative $\mathbf{2 1}$ and 28-O-bromoacetylbetulin 12 showed good anti-leishmanial activity at $50 \mu \mathrm{M}$, inhibiting 53 and $56 \%$ of the intracellular parasites, respectively (compared with 69 and 86\% inhibition using axenic amastigotes in the microplate assay, respectively). At $25 \mu \mathrm{M}, 28$-O-bromoacetylbetulin 12 still had the best activity of the compounds examined showing $34 \%$ inhibition, dihydrobetulonic acid 19 and L-aspartyl amide derivative 
Table 1 Anti-leishmanial activities at $50 \mu \mathrm{m}$ on microplate assay and $\mathrm{GI}_{50}$ values for the most potent synthetic betulin derivatives against Leishmania donovani axenic amastigotes

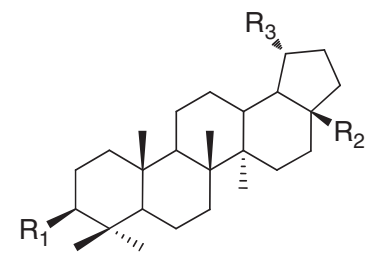

\begin{tabular}{|c|c|c|c|c|c|}
\hline Compound & $R_{I}$ & $R_{2}$ & $R_{3}$ & $\begin{array}{c}\text { Inhibition (\%) } \\
\text { at } 50 \mu M\end{array}$ & $\begin{array}{l}G I_{50} \\
(\mu M)\end{array}$ \\
\hline 1 & $\mathrm{OH}$ & $\mathrm{CH}_{2} \mathrm{OH}$ & $\mathrm{CH}_{3}-\mathrm{C}=\mathrm{CH}_{2}$ & 35.0 & \\
\hline 6 & $\mathrm{OH}$ & & $\mathrm{CH}_{3}-\mathrm{C}=\mathrm{CH}_{2}$ & 0.0 & \\
\hline 7 & $\mathrm{OH}$ & & $\mathrm{CH}_{3}-\mathrm{C}=\mathrm{CH}_{2}$ & 8.8 & \\
\hline 8 & $\mathrm{OH}$ & & $\mathrm{CH}_{3}-\mathrm{C}=\mathrm{CH}_{2}$ & 10.5 & \\
\hline 9 & $\mathrm{OH}$ & & $\mathrm{CH}_{3}-\mathrm{C}=\mathrm{CH}_{2}$ & 13.4 & \\
\hline 10 & $\mathrm{OH}$ & & $\mathrm{CH}_{3}-\mathrm{C}=\mathrm{CH}_{2}$ & 16.6 & \\
\hline 11 & $\mathrm{OH}$ & & $\mathrm{CH}_{3}-\mathrm{C}=\mathrm{CH}_{2}$ & 59.2 & \\
\hline 12 & $\mathrm{OH}$ & & $\mathrm{CH}_{3}-\mathrm{C}=\mathrm{CH}_{2}$ & 86.0 & 34.9 \\
\hline 13 & OAc & $\mathrm{OH}$ & $\mathrm{CH}_{3}-\mathrm{C}=\mathrm{CH}_{2}$ & 37.4 & \\
\hline 14 & OAc & $\mathrm{CH}_{2} \mathrm{OAc}$ & $\mathrm{CH}_{3}-\mathrm{C}=\mathrm{CH}_{2}$ & 0.0 & \\
\hline 15 & & & $\mathrm{CH}_{3}-\mathrm{C}=\mathrm{CH}_{2}$ & 0.0 & \\
\hline 4 & $\mathrm{OH}$ & $\mathrm{CHO}$ & $\mathrm{CH}_{3}-\mathrm{C}=\mathrm{CH}_{2}$ & 64.3 & \\
\hline 2 & $\mathrm{OH}$ & $\mathrm{CO}_{2} \mathrm{H}$ & $\mathrm{CH}_{3}-\mathrm{C}=\mathrm{CH}_{2}$ & 39.8 & \\
\hline 16 & $\mathrm{O}=$ & $\mathrm{CH}_{2} \mathrm{OAc}$ & $\mathrm{CH}_{3}-\mathrm{C}=\mathrm{CH}_{2}$ & 40.6 & \\
\hline 17 & $\mathrm{O}=$ & $\mathrm{CHO}$ & $\mathrm{CH}_{3}-\mathrm{C}=\mathrm{CH}_{2}$ & 46.2 & \\
\hline 18 & $\mathrm{O}=$ & $\mathrm{CO}_{2} \mathrm{H}$ & $\mathrm{CH}_{3}-\mathrm{C}=\mathrm{CH}_{2}$ & 97.6 & 14.6 \\
\hline 19 & $\mathrm{O}=$ & $\mathrm{CO}_{2} \mathrm{H}$ & $\mathrm{CH}_{3} \mathrm{CHCH}_{3}$ & 72.1 & 56.0 \\
\hline 20 & $\mathrm{O}=$ & $\mathrm{CO}_{2} \mathrm{Me}$ & $\mathrm{CH}_{3}-\mathrm{C}=\mathrm{CH}_{2}$ & 40.1 & \\
\hline 21 & $\mathrm{O}=$ & & $\mathrm{CH}_{3}-\mathrm{C}=\mathrm{CH}_{2}$ & 69.3 & 21.2 \\
\hline 22 & $\mathrm{O}=$ & & $\mathrm{CH}_{3}-\mathrm{C}=\mathrm{CH}_{2}$ & 0.0 & \\
\hline 23 & - & $\mathrm{CH}_{2} \mathrm{OH}$ & $\mathrm{CH}_{3}-\mathrm{C}=\mathrm{CH}_{2}$ & 13.2 & \\
\hline 24 & $\mathrm{OH}$ & $\mathrm{CH}=\mathrm{NOH}$ & $\mathrm{CH}_{3}-\mathrm{C}=\mathrm{CH}_{2}$ & 69.1 & \\
\hline 25 & $=\mathrm{NOH}$ & $\mathrm{CH}=\mathrm{NOH}$ & $\mathrm{CH}_{3}-\mathrm{C}=\mathrm{CH}_{2}$ & 72.9 & 22.8 \\
\hline 26 & OAc & $\mathrm{CN}$ & $\mathrm{CH}_{3}-\mathrm{C}=\mathrm{CH}_{2}$ & 62.7 & \\
\hline $\begin{array}{l}\text { Positive } \\
\text { control }^{\text {a }}\end{array}$ & & & & 95 & \\
\hline $\begin{array}{l}\text { Negative } \\
\text { control }^{\mathrm{b}}\end{array}$ & & & & 0.0 & \\
\hline
\end{tabular}

Abbreviation: DMSO, dimethyl sulfoxide.

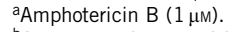

bCulture medium+DMSO

21 were only weakly active at this concentration. Finally, at $12.5 \mu \mathrm{M}$ concentration, oxime derivative $\mathbf{2 5}$ showed the best anti-leishmanial activity with a 52\% inhibition, whereas L-aspartyl amide derivative $\mathbf{2 1}$ was totally inactive and the rest showed only weak activity.
We have shown that by simple chemical modification, anti-leishmanial activity of ubiquitous naturally occurring triterpene, betulin, can be improved considerably. It is possible to derive relatively potent anti-leishmanial compounds with low micromolar $\mathrm{GI}_{50}$ values. In 
Table 2 Cytotoxicity of the most potent synthetic betulin derivatives on macrophage cell line THP-1

\begin{tabular}{lrcr}
\hline & \multicolumn{3}{c}{ Inhibition of growth (\%) } \\
\cline { 2 - 4 } Compound & $50 \mu \mathrm{m}$ & $25 \mu \mathrm{m}$ & $12.5 \mu \mathrm{m}$ \\
\hline $\mathbf{1 2}$ & 0.0 & 0.0 & 0.0 \\
$\mathbf{1 8}$ & 85.3 & 77.7 & 38.2 \\
$\mathbf{1 9}$ & 80.2 & 30.0 & 22.0 \\
$\mathbf{2 1}$ & 0.0 & 14.0 & 3.6 \\
$\mathbf{2 5}$ & 61.4 & 55.2 & 13.6 \\
\hline
\end{tabular}

Table 3 Anti-leishmanial activities of the most potent synthetic betulin derivatives against macrophage cell line THP-1 infected with Leishmania donovani

\begin{tabular}{lccr}
\hline & \multicolumn{3}{c}{ Inhibition of growth (\%) } \\
\cline { 2 - 4 } Compound & $50 \mu \mathrm{m}$ & $25 \mu \mathrm{M}$ & $12.5 \mu \mathrm{m}$ \\
\hline $\mathbf{1 2}$ & 56.3 & 34.4 & 17.8 \\
$\mathbf{1 9}$ & $\mathrm{nt}$ & 20.6 & 14.3 \\
$\mathbf{2 1}$ & 53.3 & 16.0 & 0.0 \\
$\mathbf{2 5}$ & $\mathrm{nt}$ & $\mathrm{nt}$ & 51.5
\end{tabular}

Abbreviation: nt, not tested because the toxicity to the THP-1 cell line was $>30 \%$ at that concentration.

general, carbonyl or carboxyl groups at C-3 or C-28 have a beneficial effect in anti-leishmanial inhibition activity, and these compounds can be regarded as significant lead molecules for further improvement and optimization. Further studies are required to develop more potent betulin derivatives with leishmanicidal properties, and with no toxicity in macrophage cell lines or in human host cells. Moreover, thorough early ADME, biological mechanism and animal studies are required to evaluate anti-leishmanial activity in vivo.

\section{EXPERIMENTAL SECTION}

Chemical syntheses of betulin derivatives screened in this study for antileishmanial activity are described in detail elsewhere. ${ }^{18}$ Anti-leishmanial activities of betulin derivatives were screened using a fluorescent viability microplate assay with $L$. donovani (MHOM/SD/1962/1S-Cl2d) axenic amastigotes and alamarBlue (resazurin, AbD Serotec, Oxford, UK) as described previously. ${ }^{19-21}$ Initial screening was carried out by assessing the inhibition of amastigote growth at $50 \mu \mathrm{m}$ of betulin derivative. All compounds were tested at least twice in triplicate. Complete medium, both with and without dimethyl sulfoxide, was used as negative controls ( $0 \%$ inhibition of amastigote growth). The most potent betulin derivatives from initial screening were selected for further investigation. For these compounds, the $\mathrm{GI}_{50}$ value (concentration for $50 \%$ growth inhibition) was also determined, as well as screening for activity on infected macrophages. The latter assay was carried out as previously described using the retinoic acid-treated human macrophage cell line THP-1 infected with $L$. donovani expressing the luciferase gene ( $L d$ :pSSU-int/LUC) at a $3: 1$ parasite:macrophage ratio. ${ }^{17,22}$ Compounds (at 50,25 and $12.5 \mu \mathrm{M}$ ) to be tested were added for $48 \mathrm{~h}$, and luminescence was determined after adding a luciferase substrate and measuring in a microplate reader. Amphotericin B was included as a positive control on each plate and resulted in $>90 \%$ inhibition at $1 \mu \mathrm{M}$. The effect of compounds on THP-1 cells alone was assessed using the alamarBlue viability assay.

\section{ACKNOWLEDGEMENTS}

This study was supported by the Finnish Funding Agency for Technology and Innovation (Tekes), the Foundation for Research of Natural Resources in Finland, Marjatta ja Eino Kollin Säätio and the European Commission (Contract nos LSHB-CT-2004-503467 and EU-KBBE-227239-ForestSpeCs). We thank Mrs Anja Salakari and Mr Erkki Metsälä for their excellent technical assistance. Dr Salme Koskimies is thanked for valuable discussions. CLJ holds the Michael and Penny Feiwel Chair in Dermatology and is grateful to the American Friends of Hebrew University for financial support of this project.

1 Chan-Bacab, M. J. \& Pena-Rodriguez, L. M. Plant natural products with leishmanicidal activity. Nat. Prod. Rep. 18, 674-688 (2001).

2 Jha, T. K. et al. Miltefosine, an oral agent, for the treatment of Indian visceral leishmaniasis. N. Engl. J. Med. 341, 1795-1800 (1999).

3 Pink, R., Hudson, A., Mouries, M- A. \& Bendig, M. Opportunities and challenges in antiparasitic drug discovery. Nat. Rev. Drug Discov. 4, 727-740 (2005).

4 Berman, J. et al. Miltefosine: issues to be addressed in the future. Trans. Roy. Soc. Trop. Med. Hyg. 100S, S41-S44 (2006).

5 Eckerman, C. \& Ekman, R. Comparison of solvents for extraction and crystallisation of betulinol from birch bark waste. Pap. Puu 67, 100-106 (1985).

$6 \mathrm{Kim}$, D.S.H.L. et al. A concise semi-synthetic approach to betulinic acid from betulin. Synth. Commun. 27, 1607-1612 (1997).

7 Mukherjee, P. K., Saha, K., Das, J., Pal, M. \& Saha, B. P. Studies on the antiinflammatory activity of rhizomes of Nelumbo nucifera. Planta Med. 63, 367-369 (1997).

8 Steele, J. C. P., Warhust, D. C., Kirby, G. C. \& Simmonds, M. S. J. In vitro and in vivo evaluation of betulinic acid as an antimalarial. Phytother. Res. 13, 115-119 (1999).

9 Fulda, S. et al. Betulinic acid triggers CD95 (APO-1/Fas)- and p53-independent apoptosis via activation of caspases in neuroectodermal tumors. Cancer Res. 57, 4956-4964 (1997).

10 Pisha, E. et al. Discovery of betulinic acid as a selective inhibitor of human melanoma that functions by induction of apoptosis. Nat. Med. 1, 1046-1051 (1995).

11 Kanamoto, T. et al. Anti-human immunodeficiency virus activity of YK-FH312 (a betulinic acid derivative), a novel compound blocking viral maturation. Antimicrob. Agents Chemother. 45, 1225-1230 (2001).

12 Soler, F. et al. Betulinic acid derivatives: a new class of specific inhibitors of human immunodeficiency virus type 1 entry. J. Med. Chem. 39, 1069-1083 (1996).

13 Alakurtti, S., Mäkelä, T., Koskimies, S. \& Yli-Kauhaluoma, J. Pharmacological properties of the ubiquitous natural product betulin. Eur. J. Pharm. Sci. 29, 1-13 (2006).

14 Chowdhury, A. R. et al. Dihydrobetulinic acid induces apoptosis in Leishmania donovani by targeting DNA topoisomerase I and II: Implications in antileishmanial therapy. Mol. Med. 9, 26-36 (2003).

15 Takahashi, M., Fuchino, H., Sekita, S. \& Satake, M. In vitro leishmanicidal activity of some scarce natural products. Phytother. Res. 18, 573-578 (2004).

16 Sauvain, M. et al. Isolation of leishmanicidal triterpenes and lignans from the Amazonian liana Doliocarpus dentatus (Dilleniaceae). Phytother. Res. 10, 1-4 (1996).

17 Alakurtti, S. et al. Synthesis and anti-leishmanial activity of heterocyclic betulin derivatives. Bioorg. Med. Chem. doi:10.1016/j.bmc.2010.01.003 (in press) (2010).

18 Pohjala, L., Alakurtti, S., Ahola, J. T., Yli-Kauhaluoma, J. \& Tammela, P. Betulinderived compounds as inhibitors of alphavirus replication. J. Nat. Prod. 72, 1917-1926 (2009).

19 Debrabant, A., Joshi, M. B., Pimenta, P. F. P. \& Dwyer, D. M. Generation of Leishmania donovani axenic amastigotes: their growth and biological characteristics. Int. J. Parasitol. 34, 205-217 (2004).

20 Mikus, D. \& Steverding, D. A. A simple colorimetric method to screen drug cytotoxicity against Leishmania using the dye Alamar Blue. Parasitol. Int. 48, 265-269 (2000).

21 Shimony, O. \& Jaffe, C. L. Rapid fluorescent assay for screening drugs on Leishmania amastigotes. J. Microbiol. Methods 75, 196-200 (2008).

22 Hemmi, H. \& Breitman, T. Induction of functional differentiation of a human monocytic leukemia cell line (THP-1) by retinoic acid and cholera toxin. Jpn. J. Cancer Res. 76, 345-351 (1985). 